
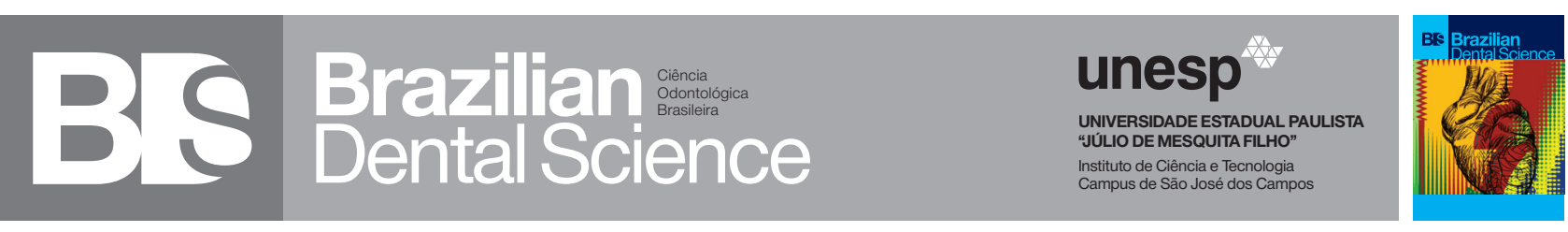

\title{
(4)
}

\section{Biological restoration in permanent tooth: four-year follow-up}

Restaurações biológicas em dentes permanentes: acompanhamento de 4 anos

Rafael MENEZES-SILVA ${ }^{1}$, Leticia Pena BOTELHO ${ }^{2}$, Adriana Maria BOTELHO ${ }^{2}$, Karine Taís Aguiar TAVANO ${ }^{2}$

1 - Department of Dentistry, Endodontics and Dental Materials - Bauru Dental School - University of São Paulo - Bauru - SP - Brazil.

2 - Department of Dentistry - Federal University of "Vales do Jequitinhonha e Mucuri" - Diamantina - MG - Brazil.

\section{ABSTRACT}

Biological restorations, involving a technique of uniting autogenous or homogenous dental fragment for use as the primary restorative material, are an alternative for morphological and functional reestablishment of teeth with extensive coronal destruction. Despite the wide range of restorative materials available in dentistry, no material has proved to be as efficient as the natural tooth structure. This article illustrates a therapeutic option for rehabilitating a devitalized mandibular tooth with a weakened coronal remainder by using the biological restoration technique. The authors present the sequence of planning and performing the technique, such as the characteristics of preparation of the tooth and fragment, impression taking, cutting and cementation of the fragment, and the four-year follow-up of the biological restoration, which shows the success of the technique with marginal adaptation and satisfactory esthetic appearance.

\section{KEYWORDS}

Adhesive; Devitalized tooth; Permanent dental restorations.

\section{RESUMO}

As restaurações biológicas, envolvendo uma técnica de união de fragmentos dentários autógenos ou homogêneos como principal material restaurador, são uma alternativa para o restabelecimento morfológico e funcional de dentes com destruição coronal extensa. Apesar da ampla gama de materiais restauradores disponíveis na odontologia, nenhum material provou ser tão eficiente quanto a estrutura dentária natural. Este artigo ilustra uma opção terapêutica para reabilitar um molar inferior desvitalizado com um remanescente coronal fragilizado, utilizando a técnica de restauração biológica. Os autores apresentam a sequência de planejamento e execução da técnica, tais como as características de preparação do dente e do fragmento, moldagem, recorte e cimentação do fragmento, e o acompanhamento clínico de 3 anos da restauração biológica, mostrando o sucesso da técnica com uma adaptação marginal e aparência estética satisfatória.

\section{PALAVRAS-CHAVE}

Adesivos; Dente não Vital; Restaurações dentárias permanentes.

\section{INTRODUCTION}

A mong the wide range of materials existent in Restorative Dentistry, no material has proved to be as efficient as the natural structure, considering the mechanical and biological properties [1].

Biological restoration is a restorative technique in which a tooth fragment obtained from an extracted tooth, which was duly donated, is used as the main restorative material [2]. The term biological restoration was proposed by Santos and Bianchi [3] and is characterized by its primary restorative material being the dental substrate, dentin and enamel, to designate fragment bonding to both anterior and posterior teeth; this may be an autogenous bond, when the fragment has been obtained from the fractured tooth itself, or from a tooth extracted from the patient him/herself [2]. A homogenous bond 
may also be considered when the fragment has been cut from a donated tooth [4].

Initially, this technique was recommended for primary teeth, particularly in anterior teeth [1-3]. In this study, the technique has been proposed as an alternative for the morphological and functional re-establishment of permanent posterior teeth with extensive coronal destruction as proposed by Botelho et al. [5].

According to Alcântara et al. [2], biological restoration has shown to be a good option owing to its having advantages such as low cost, biocompatibility, preservation of all the natural characteristics of the teeth, including color, anatomic contours, shine, surface smoothness, and the maintenance of levels of function and physiological wear similar to those of the neighboring teeth. Furthermore, there is the highly favorable emotional impact on the patient, who gets the feeling of having regained a healthy tooth $[4,6]$. Nevertheless, some limitations are inherent to this technique, such as the difficulty in finding a tooth that has been stored in compliance with established ethical principles and with the same characteristics of color and size similar to those of the remainder of the tooth, and the patient's refusal to accept a tooth from another individual $[6,7]$.

The aim of this article was to demonstrate biological restoration as an alternative technique for esthetic and functional recovery of posterior teeth with extensive coronal destruction, including its advantages and disadvantages, by describing a clinical case.

\section{CASE REPORT}

The patient, a 25-year-old man, presented to the Dental Clinic of the Federal University of the "Vales do Jequitinhonha e Mucuri", Diamantina, Brazil, with an extensive resin restoration in the mandibular right permanent second molar that was shown to be fractured (Figure 1). Radiographic exams revealed satisfactory endodontic treatment, so that no re-treatment was necessary. The restorative treatment suggested to the patient was biological restoration (homogenous fragment bonding).

The technique was explained to the patient, who was given information about its advantages and disadvantages, as well as about other treatment options. On agreeing to the use of the biological restoration technique, the patient signed the Informed Consent Form.

During the first consultation, the unsatisfactory resin restoration (Figure 1) was removed, and a filling core was constructed with Vitremer resin modified glass ionomer cement (Vitremer, 3M ESPE, St. Paul, USA).

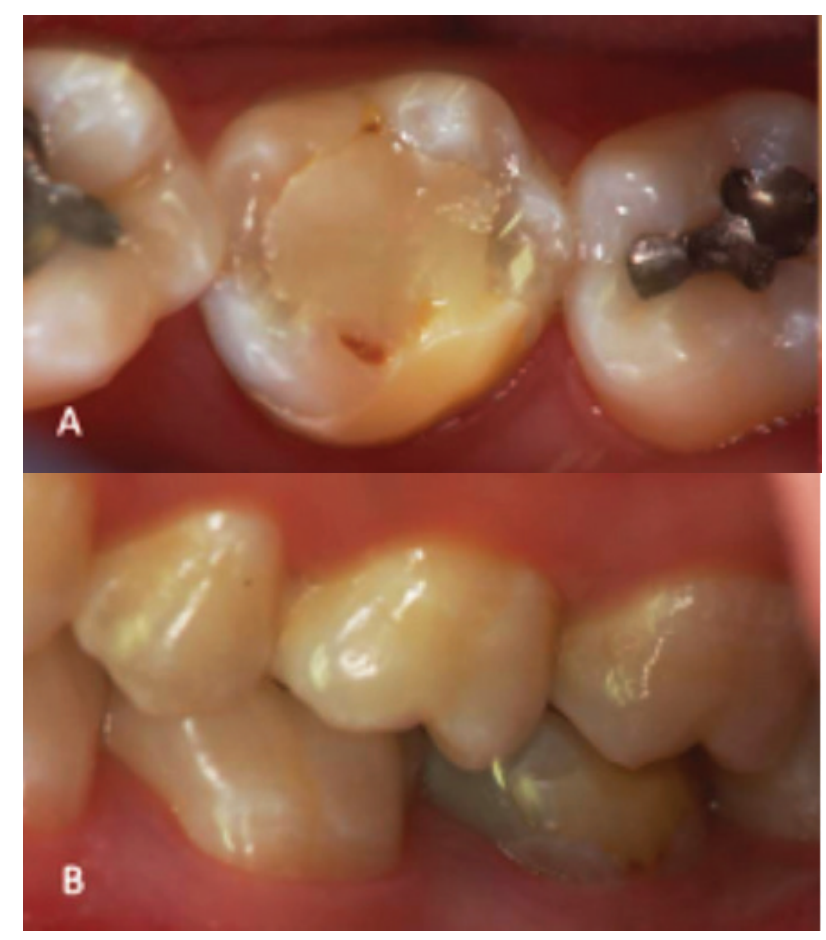

Figure 1 - Initial clinical exam (A) Occlusal view, presenting extensive resin on the occlusal and vestibular surfaces. (B) Vestibular view, with extensive unsatisfactory resin.

In the second session, the remainder of the tooth was prepared with cylindrical diamond tips with rounded extremity to allow a minimum thickness of $2 \mathrm{~mm}$ for the restoration and thus guarantee a fragment with enamel and dentin throughout its full extent $[2,8,9]$. The preparation consisted of occlusal wear involving all cusp and marginal ridges due to severe coronary destruction. By vestibular, the extensive resin restoration had to be removed, leaving the preparation on this face at the gingival level. By lingual, due the cusp being undermined and weakened, these were lowered in such a way as to ensure a minimum thickness to the fragment. The preparation terminus was maintained in a rounded enamel shoulder. An orifice 
was made in the filling core to serve as a fragment adaptation guide at the time of cementation (Figure 2). Addition silicone (Optosil Xantopren, São Paulo, SP, Brazil) was used to take a direct impression of the maxillary right permanent second molar, the antagonist tooth, and the bite register. The temporary restoration was fabricated. The casts were obtained in special Durone type IV plaster (Dentsply, Petrópolis, RJ, Brazil) and mounted in a semi-adjustable articulator in maximum habitual intercuspidation (MHI).

A donated tooth was selected, presenting color and size characteristics similar to those of the remaining tooth to be restored (Figure 3), and submitted to sterilization in an autoclave at $121^{\circ} \mathrm{C}$ for 15 minutes, in compliance with biosafety regulations [10].

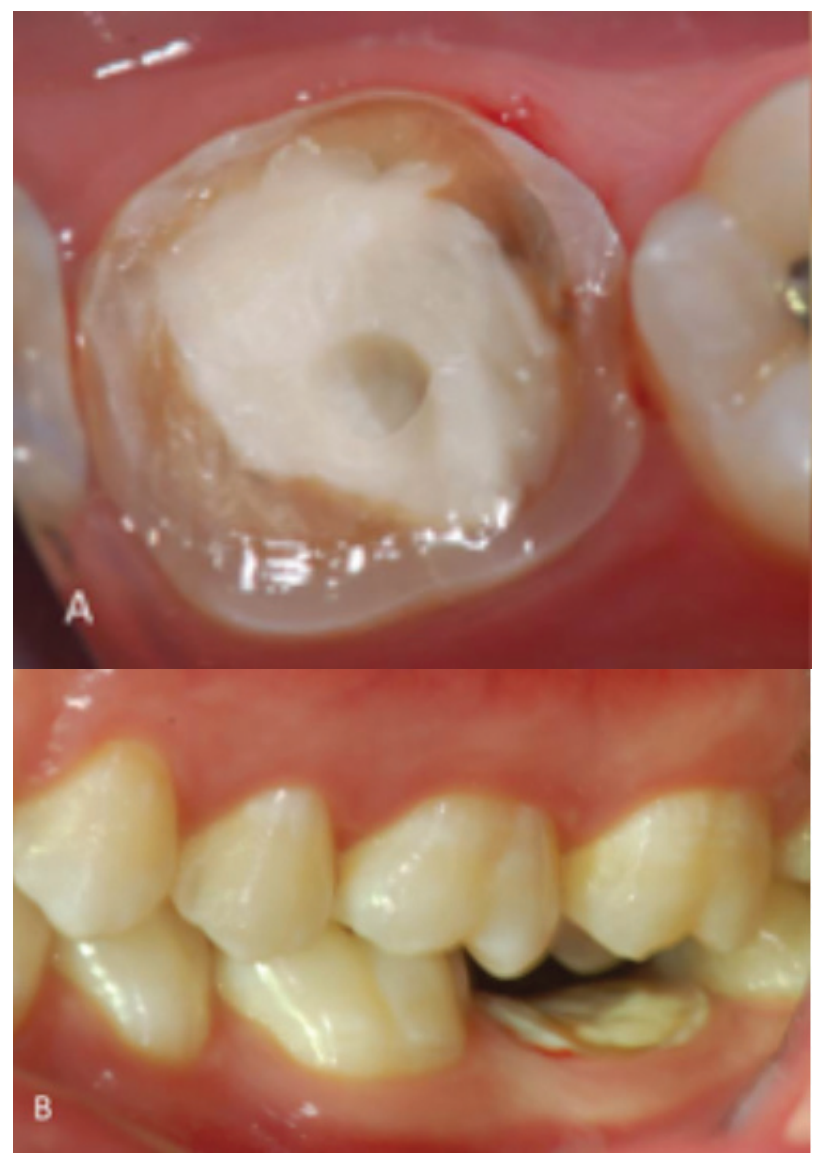

Figure 2 - Preparation of remainder of the tooth (A) Occlusal view, observe sufficient thickness of preparation, maintaining the terminal in enamel and adaptation guide. (B) Vestibular view.
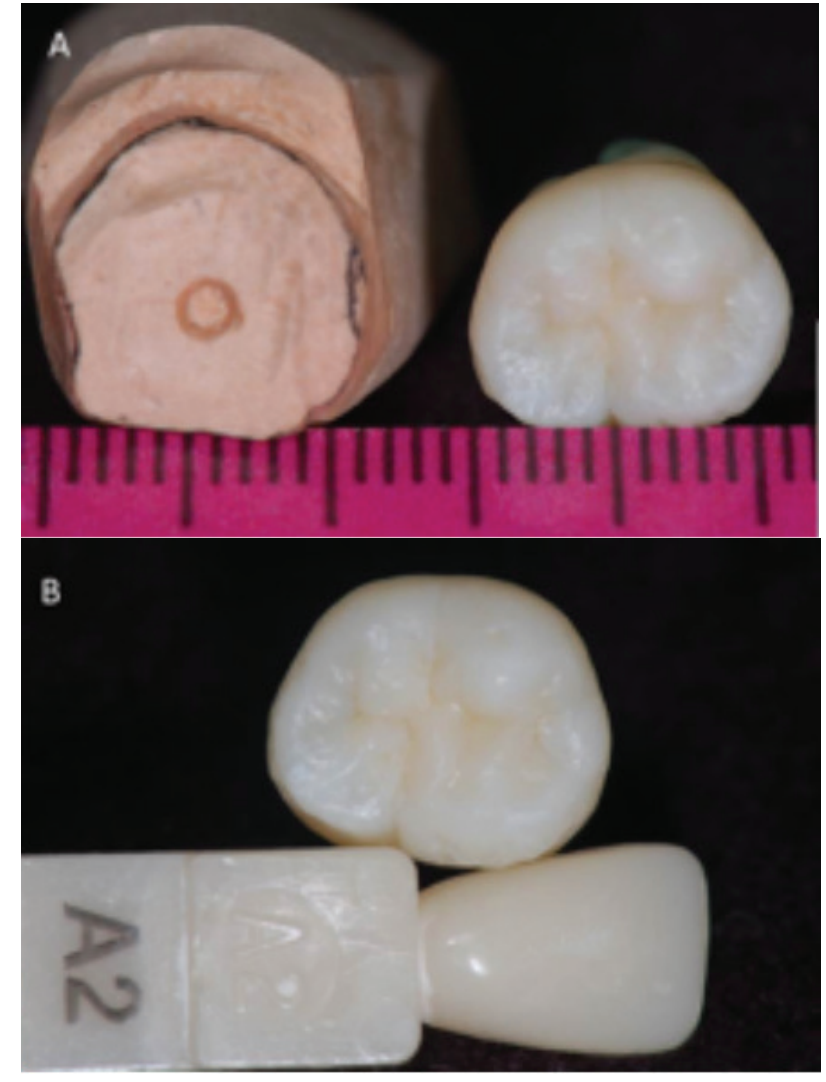

Figure 3 - Tooth selection (A) Tooth with dimension similar to that of the preparation. (B) Shade selection according to the remainder.

The tooth was sectioned, separating the coronal portion (to be used for cutting the fragment) from the root portion (Figure 4A), which was stored for other research purposes. Using the spherical and cylindrical diamond tips, under intense cooling, the coronal portion was cut until there was maximum adaptation of the fragment obtained (Figure 4B) to the plaster cast (Figures 4C and 4D). For complete cervical adaptation, the fragment was relined together with the die by using light activated resin composite Filtek Z-350 (3M-ESPE, St. Paul, USA), after etching with $37 \%$ phosphoric acid (Dentalville, Joinville-SC, Brazil) (Figure 5A) and application of the adhesive system Adper Single Bond (Irvine, California, USA) (Figure 5B). The first occlusal adjustments had been made at the laboratory stage to facilitate clinical adaptation afterwards. 

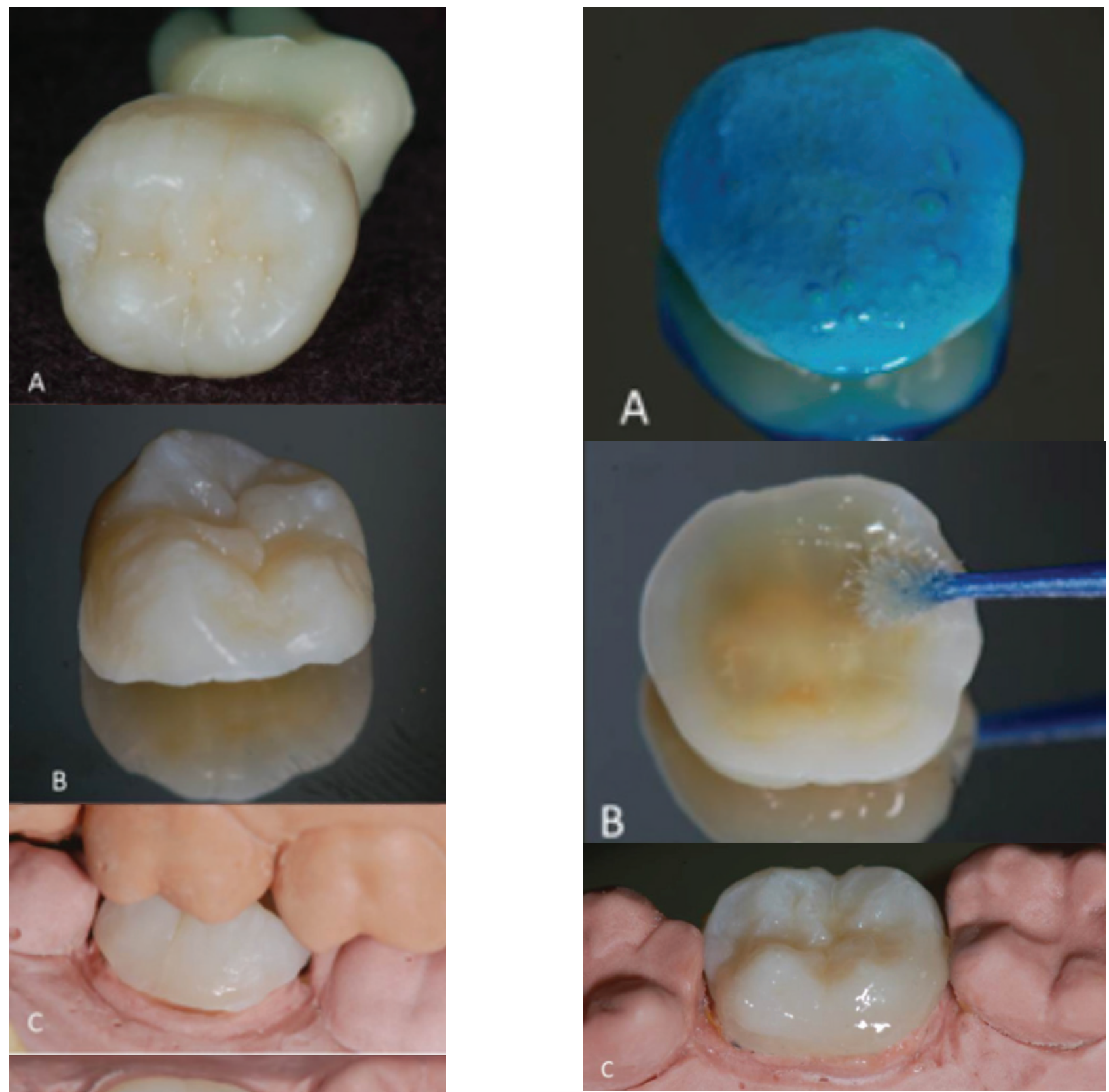

Figure 5 - Cervical adaptation. (A) Etching with 37\% phosphoric acid (B) Application of the adhesive system. (C) Cervical adaptation on plaster cast with use of light activated resin composite.

Figure 4 - Section and adaptation of the tooth. (A) Section of the coronal part. (B) Proximal view of fragment. (C) Adaptation of fragment to plaster cast. (D) Occlusal view, note the proximal contacts. 
The fragment was tested in a new clinical session. The proximal contacts were evaluated by dental floss. The cervical adaptation (Figure 6) was verified by means of an interproximal radiograph, where one can confirm it with respect to the vertical and horizontal biological space, as well as the correct emergency profile. The region was partially isolated, and the procedures were performed for adhesive cementation with self-adhesive dual polymerization Rely X U-200 adhesive (3M-ESPE, Seefeld, Germany). Procedures began by etching with $37 \%$ phosphoric acid (Dentalville, Joinville-SC, Brazil) in enamel for 15 seconds for both the remainder of the tooth and the fragment. These were washed and dried and, subsequently, the cement was manipulated and inserted into the fragment that was positioned on the remainder of the tooth. The excess cement was removed with an exploratory probe and dental floss, and then all the surfaces were light polymerized for 40 seconds. Occlusion was tested to prevent premature contacts and discomfort to the patient. The patient was given instructions about proper care with cleaning and diet to prevent recurrent caries, since the behavior of the restoration would be similar to that of the other healthy teeth. Figure 7 illustrates the final clinical and radiographic aspects of the restoration.

After four years follow-up, the authors observed successful treatment, with maintenance of full marginal adaptation and favorable function and esthetics (Figure 8).

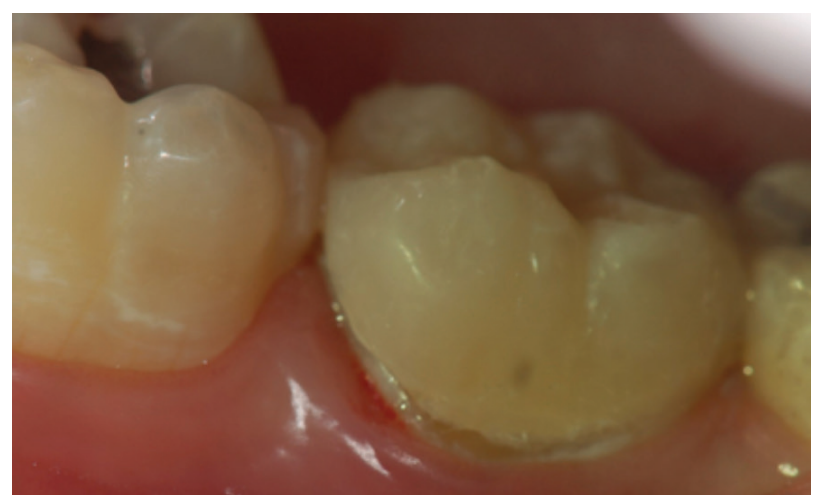

Figure 6 - Adjustment of fragment on remainder of the tooth. Cervical adaptation on remainder of the tooth.

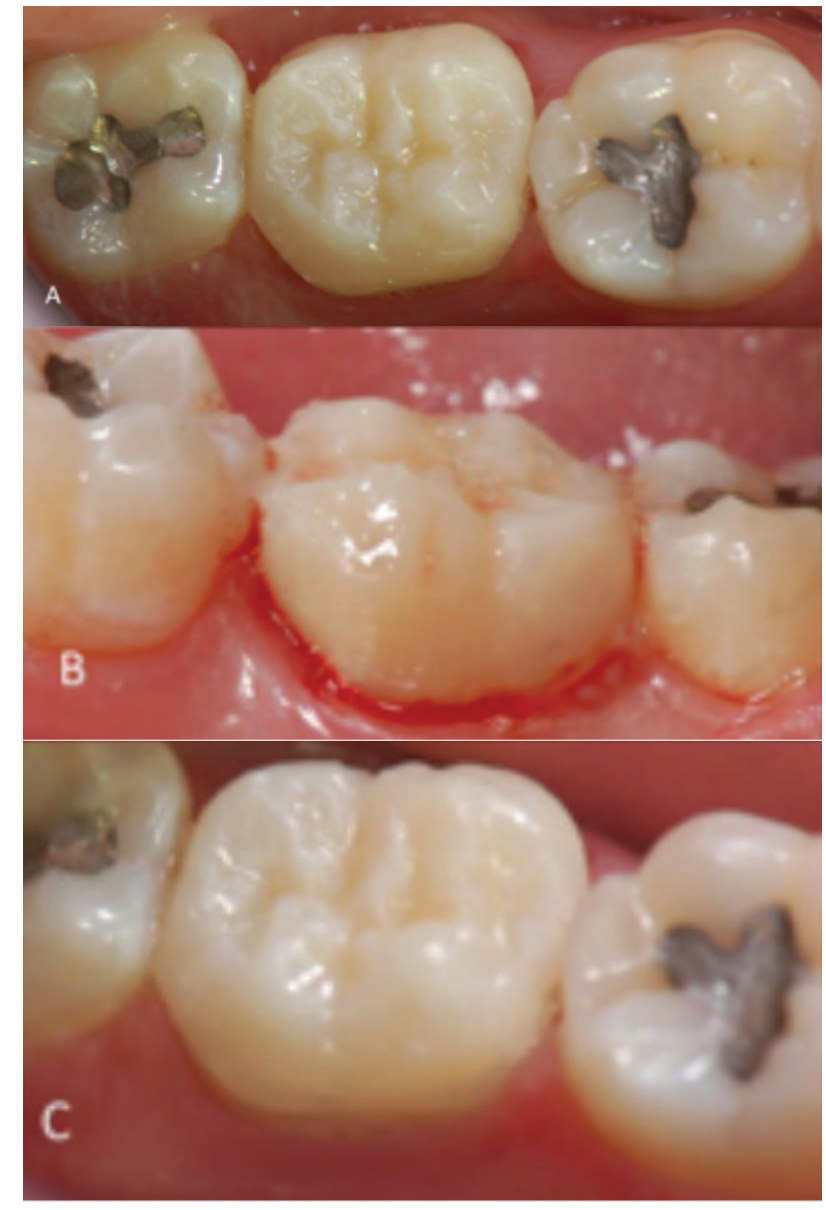

Figure 7 - Cementation of the fragment. (A) Occlusal view, satisfactory proximal contacts. (B) Removal of excess resin cement. (C) After polymerization.

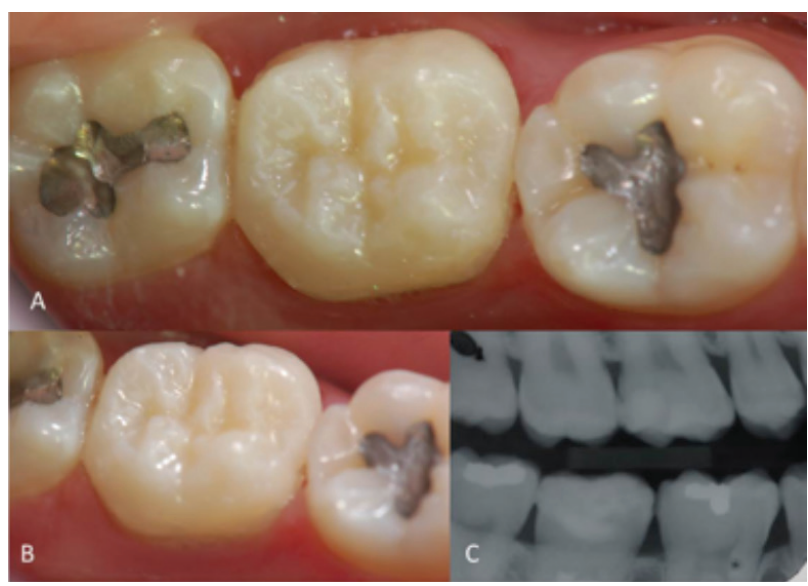

Figure 8 - Follow-up after four years. (A) Occlusal view, note maintenance of the proximal contacts. (B) Vestibular view. (C) Follow-up radiograph showing integrity of the fragment adaptation. 


\section{DISCUSSION}

Biological restoration may be considered an efficient restorative alternative, since it achieves functional and esthetic standards similar to those of natural teeth $[2,6,8]$.

Its advantages include the natural recovery of the anatomy, color, brightness, and surface smoothness of the enamel, in addition to a physiological wear, due to being a more conservative preparation. The psychosocial factor is also of great relevance, as is the low cost $[11,12]$.

The difficulty in selecting teeth with a color and shape similar to those of the remainder to be restored, within the ethical principles, are limitations to using the technique. The creation of more human tooth banks would minimize the difficulties by obtaining teeth for this technique, in addition to providing teeth for didactic, clinical, and scientific purposes. A limitation to consider when the homogenous technique is used is the patients' resistance to receiving a restoration in which the main restorative material is a fragment from a donated tooth [4].

It is important to point out that, in the fragment bonding technique, there are factors that require greater attention. For instance, the selected tooth must be completely hydrated, since there is distinct possibility of fractures occurring while the fragment is being cut. Dehydration of the fragment may harm the bond of the adhesive cementing agent, because the dehydrated dentin will not provide the formation of the hybrid layer in an appropriate manner $[13,14]$. The process of sterilizing extracted human teeth has been studied by many authors to verify the influence of each method on the properties of the enamel and dentin and, consequently, the quality of adhesion to the resinous adhesive materials. There is a consensus on the importance of tooth sterilization prior to any manipulation [15-19]. Humid heat is considered an effective sterilizing method as it does not influence the adhesive properties, according to De Wald [15] and Pashley, Tao, Pashley [16]. However, Lee et al. [17] disagree, noting that sterilization with autoclaving adversely affects the adhesive strength of specimens and that the most effective method would be $10 \%$ formalin.

The preparation must be made in a way that will allow a minimum enamel and dentin thickness in the fragment/restoration to avoid fractures. The smaller the details such as boxes, retention channels, and beveled terminal are, the easier it will be to cut the fragment. The authors also observed that prior cervical relining of the fragment to the die prevented marginal gaps that would have to be filled with cement, because such gaps are inevitable due to manual cutting, and prior relining also allowed adequate polishing of the margins $[2,4,9]$. Because it is a technique performed by manually adapting it to the mold, there will always be marginal gaps, minimized by reassembly in the laboratory with composite resin. Clinical and radiographic followup after four years indicates the success of these restorations. It is important to note that respect for biological distances and preservation of occlusal and proximal contacts should be observed during the procedures. During the clipping, the professional should be aware of details such as the devolution of a correct emergency profile for adequate periodontal maintenance.

Compared with other materials used in indirect restorations, such as ceramics or metal restorations, biological restoration represents an important alternative for the low-income population, because indirect restorations are generally outsourced. Biological restorations are also performed with donated teeth or those from patients themselves; they are fabricated from the human organ and, therefore, there is no charge for the restorative material.

It must be made clear that the teeth used in biological restorations are submitted to a strict sterilization process, providing the patient with complete safety [20]. 
The advantages of biological restorations are related to the quality of the restorative material. These are the natural characteristics inherent to the enamel/dentin itself, such as surface smoothness, brightness, translucence, opacity, anatomy, and hardness. Since restoration is a biological structure, the risks of recurrent caries on the occlusal and proximal surfaces must be emphasized. These risks are the same as they are for the other teeth, because e restoration is subjected to the oral process of remineralizationtb and demineralization.

The success of a biological restoration is directly linked to the patient's cooperation, who must be instructed about oral hygiene. Followup must be made every six months, because the restoration is subject to the development of caries.

Therefore, longitudinal studies need to be conducted to verify the long-term behavior of the mechanical and biological properties of these restorations.

\section{CONCLUSION}

In spite of some limitations, the biological restoration technique was an economical and successful alternative for the treatment of teeth with extensive coronal destruction, as it provided excellent functional and esthetic results.

\section{REFERENCES}

1. Wadhwani KK, Hasija M, Meena B, Wadhwa D, Yadav R. Biological restorations: Option of reincarnation for severely mutilated teeth. European J Gen Dent. 2013;2(1):62-6.

2. Alcântara CEP,Faria PC, Tavano KTA, Botelho AM. Fragment reattachment associated with pulpotomy in a posterior tooth with incomplete root formation. Eur J ProsthodontRestor Dent. 2011Dec;19(4):155-9.

3. Santos JFF, Bianchi J. Restoration of severely damaged teeth with resin bonding systems: case reports. Quintessence Int. 1991 Aug;22(8):611-5.

4. Tavano KTA, Botelho AM, Motta TP,Paes TMO.'Biological restoration': total crown anterior.Dent Traumatol. 2009 0ct;25(5):535-40. doi:10.1111/j.16009657.2009.00766.x. Epub2009 Aug 26.
5. Botelho AM, Tavano KTA, Correa-Faria P,Morato LNS, Viana MR. Estheticfunctional recovery of permanent posterior tooth using autogenous biological restoration J Indian Soc Pedod Prev Dent 2012 0ct-Dec;30(4):333-6 doi: 10.4103/0970-4388.108934.

6. Corrêa-FariaP,Alcântara CE, Caldas-Diniz MV, Botelho AM, Tavano KT. "Biological Restoration": Root Canal and Coronal Reconstruction. JEsthet Restor Dent. 2010 Jun;22(3):168-77. doi: 10.1111/j.1708-8240.2010.00331.x.

7. Busato AL, Loguercio AD, Barbosa AN, Sanseverino Mdo C, Macedo RP, Baldissera RA. Biological restorations using tooth fragments. Am J Dent. 1998 Feb;11(1):46-9

8. Grewal N, Seth R. Comparative in vivo evaluation of restoring severely mutilated primary anterior teeth with biological postand crown preparation and reinforced composite restoration. J Indian Soc Pedod Prev Dent.2008Dec;26(4):141-8.

9. Carvalho MFF, Botelho AM, Tavano KTA, Fernandes VCS. Biological restoration: A 4/5 crown. J Indian Soc Pedod Prev Dent. 20130ct-Dec;31(4):282-5. doi: 10.4103/0970-4388.121834.

10. Hossain MS, Balakrishnan V, Rahman NN, Sarker MZ, Kadir MO. Treatment of clinical solid waste using a steam autoclave as a possible alternative technology to incineration. Int JEnviron Res Public Health. 2012 Mar;9(3):85567. doi: 10.3390/ijerph9030855. Epub2012 Mar 9.

11. Kulkarni VK, Sharma DS, Banda NR, Solanki M, Khandewal V, Airen P.Clinical management of a complicated crown-root fracture using autogenous tooth fragment: A biological restorative approach. Contemp Clin Dent. 2013 Jan;4(1):84-7. doi:10.4103/0976-237X.111603.

12. Goenka P,Dutta S, Marwah N. Biological approach for management of anterior tooth trauma: Triple case report. J Indian Soc Pedod Prev Dent. 2011 AprJun;29(2):180-6. doi: 10.4103/0970-4388.84698.

13. Pashley DH, Agee KA, Nakajima M, Tay FR, Carvalho RM, Terada RS, etal Solvent-induced dimensional changes in EDTA-demineralized dentin matrix. J Biomed Mater Res. 2001Aug;56(2):273-81.

14. Bajad D, Sundaram N, Nazari A, Arola D. Age, dehydration and fatigue crack growth in dentin. Biomaterials. 2006 Apr;27(11):2507-17. Epub2005 Dec 9.

15. DeWald JP. The use of extracted teeth for in vitro bonding studies: a review of infection control considerations. Dent Mater. 1997 Mar;13(2):74-81.

16. Pashley EL, Tao L, Pashley DH. Sterilization of human teeth: its effect on permeability and bond strength. Am JDent. 1993 Aug;6(4):189-91.

17. Lee JJ, Nettey-Marbell A, Cook A Jr,Pimenta LA, Leonard R, Ritter AV.Using extracted teeth for research: the effect of storage medium and sterilization on dentin bond strengths. J Am Dent Assoc. 2007 Dec;138(12):1599-603.

18. Sandhu SV, Tiwari R, Bhullar RK, Bansal H, BhandariR, Kakkar T, BhusriR. Sterilization of extracted human teeth: A comparative analysis. JOral Biol Craniofac Res. 2012Sep-Dec;2(3):170-5. doi:10.1016/j.jobcr.2012.09.002. Epub 2012Sep 23

19. Salem-Milani A,Zand V,Asghari-Jafarabadi M,Zakeri-Milani P,Banifatemeh A.The effect of protocol for disinfection of extracted teeth recommended by center for disease control (CDC) on microhardness of enamel and dentin. J Clin Exp Dent.2015Dec 1;7(5):e552-6. doi:10.4317/jced.52280. eCollection2015Dec.

20. Barcelos R, Neves AA, Primo L, Souza IPR. Biological restorations as an alternative tratment for primary posterior teeth. J Clin Pediatr Dent. 2003 Summer;27(4):305-10.

\section{Rafael Menezes Silva (Corresponding address)}

Department of Dentistry, Endodontics and Dental Materials Bauru Dental School, University of São Paulo,

Al. Octávio Pinheiro Brisola, 9-75, CEP 17012-901, Bauru/

São Paulo, Brazil

Telefone: +55 1432358000

Date submitted: 2017 Jul 11

rafa18ms@hotmail.com Accept submission: 2018 0ct 23 